\title{
Atomistic and electronic structure of antisite defects in yttrium aluminum garnet: Density-functional study
}

\author{
Ana Belén Muñoz-García \\ Departamento de Química, C-XIV, Universidad Autónoma de Madrid, 28049 Madrid, Spain
}

Emilio Artacho

Department of Earth Sciences, University of Cambridge, Downing Street, Cambridge CB2 3EQ, United Kingdom

Luis Seijo

Departamento de Química, C-XIV, Universidad Autónoma de Madrid, 28049 Madrid, Spain

and Instituto Universitario de Ciencia de Materiales Nicolás Cabrera, Universidad Autónoma de Madrid, 28049 Madrid, Spain

(Received 29 April 2009; revised manuscript received 19 June 2009; published 13 July 2009)

\begin{abstract}
First-principles density-functional theory calculations have been performed on the atomistic structure, electronic structure, and distribution of antisite defects (AD) in yttrium aluminum garnet (YAG) $\mathrm{Y}_{3} \mathrm{Al}_{5} \mathrm{O}_{12}$. The formations of one and two antisite defects per unit cell are endothermic and the formation energy per defect is lower in $2 \mathrm{AD}$ than in $1 \mathrm{AD}$. In the most stable $1 \mathrm{AD}$ structure, $\mathrm{Y}$ and $\mathrm{Al}$ are as close as possible and two oxygen atoms become unbound to $\mathrm{Al}$ rising the energy of their (highest) valence levels and introducing a defect level in the gap $0.25 \mathrm{eV}$ above the top of the perfect YAG valence band. The binding energy between the individual substitutional defects $\mathrm{Y}_{\mathrm{Al}}$ and $\mathrm{Al}_{\mathrm{Y}}$ to form $1 \mathrm{AD}$ is $0.74 \mathrm{eV}$. The most stable $2 \mathrm{AD}$ structure is made of two single ADs linked together with one $\mathrm{AlO}_{6}$ moiety and it has basically the same electronic structure as the most stable $1 \mathrm{AD}$; it is the only $2 \mathrm{AD}$ structure that preserves the inversion center with respect to the unit-cell center. In this case, the binding energy between two single ADs is $0.22 \mathrm{eV}$.
\end{abstract}

DOI: 10.1103/PhysRevB.80.014105

PACS number(s): 71.55.-i, 71.15.Dx, 61.72.Bb

\section{INTRODUCTION}

Natural and synthetic garnets are important materials from the point of view of their usefulness; in particular, synthetic yttrium aluminum garnet (YAG), $\left(\mathrm{Y}_{3} \mathrm{Al}_{5} \mathrm{O}_{12}\right)$, either pure or doped with active impurities such as $\mathrm{Nd}^{3+}$ or $\mathrm{Ce}^{3+}$, is used in a wide variety of applications, such as thermal coating, optical lenses, solid-state lasers, and solid-state-lighting devices. ${ }^{1-3}$ It is well known that native defects appear in YAG during crystal growth depending on the temperature and crystallization procedure. Extended x-ray-absorption fine structure, x-ray-absorption near-edge spectroscopy and positron annihilation spectroscopy studies have established that among the intrinsic defects, antisite defects (AD) are dominant. ${ }^{4,5}$ They are known to act as shallow electron traps and they affect the structure, the luminescence, and other properties of pure $^{6}$ and doped YAG. ${ }^{7,8}$

Antisite defects appear in YAG when yttrium and aluminum atoms exchange positions. Perfect garnets are usually described in terms of a 160 atom body-centered-cubic unit cell (80 atom primitive cell), which contains 8 f.u. of $\mathrm{A}_{3} \mathrm{~B}_{2}^{\prime} \mathrm{B}_{3}^{\prime \prime} \mathrm{O}_{12}$, where $\mathrm{A}, \mathrm{B}^{\prime}$, and $\mathrm{B}^{\prime \prime}$ are cations in different symmetry sites. In YAG, $\mathrm{A} \equiv \mathrm{Y}$ is eightfold coordinated in a distorted cubic $D_{2}$ local site; this site is traditionally labeled as the dodecahedral site because the distorted cube produces a polyhedron with 12 triangular faces and we will use this term along the paper. $\mathrm{B}^{\prime} \equiv \mathrm{Al}$ is in an octahedral environment and $\mathrm{B}^{\prime \prime} \equiv \mathrm{Al}$ in a tetrahedral environment. Idealized cubic YAG belongs to the $I a \overline{3} d$ (230) space group with $\mathrm{Y}$ in 24(c) sites, $\mathrm{Al}_{\text {oct }}$ in 16 (a) sites, $\mathrm{Al}_{\text {tet }}$ in 24(d) sites, and the remaining 96 oxygen atoms in $(\mathrm{h})$ sites, which depend on three $x, y$, and $z$ internal parameters ${ }^{9}$ (Fig. 1). However, real
YAG belongs to the trigonal $R \overline{3}$ (148) space group as a consequence of the presence of antisite defects. ${ }^{4}$ In these defects, $\mathrm{B}^{\prime}$ cations $\left(\mathrm{Al}_{\mathrm{oct}}\right)$ exchange positions with $\mathrm{A}$ cations $(\mathrm{Y})$. Whereas in the higher ideal $I a \overline{3} d$ symmetry the four cube diagonals are $\overline{3}$ symmetry axis, only the [111] axis maintains this character in the lower real $R \overline{3}$ symmetry. This axis contains some of the $\mathrm{Al}_{\text {oct }}$ sites in the idealized crystal. Apart from partial experimental information on the local order around the yttrium atoms, ${ }^{10}$ little is known on the structure of the antisite defects and on their distribution.

Surprisingly, antisite defects of YAG have been the subject of very few theoretical studies. Pair-potential atomistic simulations have been performed in the framework of an empirically parametrized shell model in order to describe the

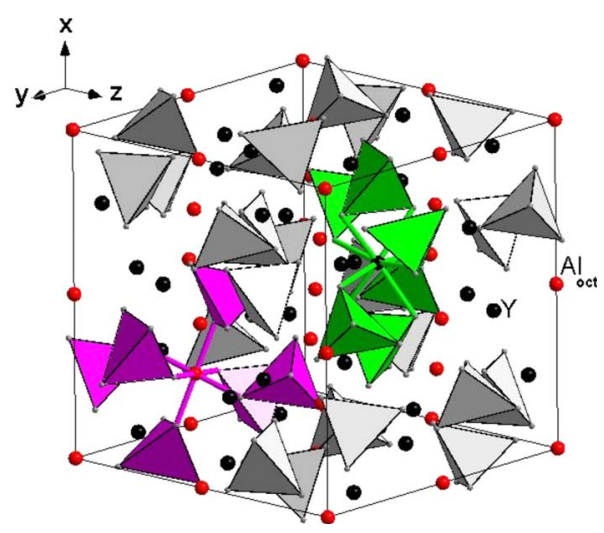

FIG. 1. (Color online) Unit cell of YAG. The yttrium ions, the aluminum ions in quasioctahedral sixfold coordinations, and the $\mathrm{AlO}_{4}$ quasitetrahedral moieties are indicated. 
energetics of formation of these and other defects such as interstitials and vacancies. ${ }^{11,12}$ These calculations concluded that antisite defects have a lower energetic demand than other kinds of intrinsic defects and that the exchange between $\mathrm{Y}$ and $\mathrm{Al}_{\text {oct }}$ is energetically preferred over the exchange between $\mathrm{Y}$ and $\mathrm{Al}_{\text {tet }}$, in agreement with the experimental observations. Regarding first-principles studies, periodic-boundary-conditions calculations of YAG and other garnets are available, ${ }^{13-18}$ and embedded-cluster calculations on the structure and the absorption and luminescence of $\mathrm{Ce}^{3+}$ substitutional defects in YAG exist, ${ }^{19}$ but we are not aware of first-principles studies on antisite defects in YAG.

Thus, the study from a first-principles point of view of the structure and energetics of antisite defects of YAG, their distribution in the host, and their electronic structure, is the primary goal of this paper. In order to do it, we carried out and analyzed first-principles periodic-boundary-conditions density-functional theory (DFT) calculations ${ }^{20,21}$ in YAG with one and two antisite defects per cubic unit cell. The details of the calculations are described in Sec. II, the results for one and two antisite defects per unit cell are shown and discussed in Sec. III, and the conclusions are presented in Sec. IV.

\section{DETAILS OF THE CALCULATIONS}

The first-principles calculations in this paper have been performed with the periodic-boundary-conditions selfconsistent SIESTA method, ${ }^{22,23}$ using DFT (Refs. 20 and 21) within the generalized gradient approximation (GGA) as formulated by Perdew, Burke, and Ernzerhof (PBE). ${ }^{24,25}$ Normconserving pseudopotentials ${ }^{26}$ in the Kleinman-Bylander form $^{27}$ have been generated for the following atoms and reference configurations: $\mathrm{Y}\left(5 s^{2} 4 p^{6} 4 d^{1}\right), \mathrm{Al}\left(3 s^{2} 3 p^{1}\right)$, and $\mathrm{O}\left(2 s^{2} 2 p^{4}\right)$, with nonlinear partial-core corrections ${ }^{28}$ and semicore states to account for large core-valence overlap in the case of Y. Atomic basis sets of a double- $\zeta$ plus polarization quality have been optimized for the three species by the fictitious enthalpy method of Anglada et al. ${ }^{29}$ in an idealized cubic $\mathrm{YAlO}_{3}$ perovskite with the following sizes: $\quad \mathrm{Y}\left(5 s 5 s^{\prime} 4 p 4 p^{\prime} 5 p 4 d 4 d^{\prime}\right), \quad \mathrm{Al}\left(3 s 3 s^{\prime} 3 p 3 p^{\prime} 3 d\right), \quad$ and $\mathrm{O}\left(2 s 2 s^{\prime} 2 p 2 p^{\prime} 3 d\right)$. These pseudopotentials and basis sets have been obtained and used previously in calculations of perfect $\mathrm{YAG}$, yttrium aluminum perovskite $\mathrm{YAlO}_{3}, \mathrm{Al}_{2} \mathrm{O}_{3}$, and $\mathrm{Y}_{2} \mathrm{O}_{3}$ with satisfactory results. ${ }^{18}$ The charge density is projected on a uniform grid in real space, with an equivalent plane-wave cutoff of $380 \mathrm{Ry}$, in order to calculate the exchange-correlation and Hartree matrix elements. Total energy calculations have been converged with respect to $k$-space integration; a $k$ grid cutoff of $15.0 \mathrm{bohr}$ was used.

All geometry optimizations have been performed without imposing any symmetry restrictions in the position of all atoms in the unit cell, using a conjugate gradient method, with a force tolerance of $0.04 \mathrm{eV} / \AA$. Starting geometries were generated from the computed atomistic structure of perfect YAG (Ref. 18) $[a=12.114 \AA, x(\mathrm{O})=-0.036, y(\mathrm{O})$ $=0.0519$, and $z(\mathrm{O})=0.1491$, in good agreement with experiment $^{9}$ ] upon exchange of $\mathrm{Y}$ and $\mathrm{Al}$ atoms to generate the antisite defects. Firstly, we optimized the structures of the single substitutional defects $\mathrm{Y}_{\mathrm{Al}}$ and $\mathrm{Al}_{\mathrm{Y}}$, in order to obtain the structures and energies of the individual defects. The 160 atoms unit cell is large enough to consider negligible the interaction between the individual substitutional defects. We found that $\mathrm{Y}_{\mathrm{Al}(\text { oct })}$ is $1.05 \mathrm{eV} /$ defect more stable than $\mathrm{Y}_{\mathrm{Al}(\text { tet })}$ (2.38 eV/defect more stable before relaxation); in consequence, all the antisite defects studied involve $\mathrm{Y}_{\mathrm{Al}(\text { oct })}$ and $\mathrm{Al}_{\mathrm{Y}}$. Then, we computed the structures and energies of all possible cases of one $\mathrm{Y}_{\mathrm{Al}}-\mathrm{Al}_{\mathrm{Y}}$ antisite defect per unit cell, 1AD:YAG. Finally, we computed a selection of all possible cases of two antisite defects per unit cell, 2AD:YAG, made after the conclusion of the 1AD:YAG study. We have explored the change in the volume of the unit cell produced by the antisite defects by allowing the cell to breath after every optimization of a defect. We obtained average volume increments of $+0.043 \%$ in $1 \mathrm{AD}$ :YAG and $+0.11 \%$ in $2 \mathrm{AD}$ : YAG. Volume effects have thus been neglected in this study, so that all the coordinates and energies in the paper correspond to $a=12.114 \AA$.

\section{RESULTS AND DISCUSSION}

\section{A. One antisite defect per unit cell, 1AD:YAG}

\section{Structure}

The local dodecahedral (distorted cube) and octahedral environments of the single substitutional defects $\mathrm{Al}_{\mathrm{Y}}$ and $\mathrm{Y}_{\mathrm{Al}}$ are shown in Fig. 2. For a reference, the calculated relaxed structures of such single defects are reflected in Table I. As we will see below, the antisite defect where $\mathrm{Al}_{\mathrm{Y}}$ and $\mathrm{Y}_{\mathrm{Al}}$ are as close as possible will take an important role and, accordingly, we will label the antisite-related oxygen atoms as $\mathrm{d} 1-\mathrm{d} 6$ if the oxygens belong to the original $\mathrm{YO}_{8}$ distorted cube (dodecahedron) only, o1-o4 if they belong to the original $\mathrm{AlO}_{6}$ octahedron only, and b1 and b2 if they are bridge atoms common to the original linked dodecahedron and octahedron.

Four different $\mathrm{Y}_{\mathrm{Al}}-\mathrm{Al}_{\mathrm{Y}}$ single antisite defects can be created with a defect concentration of $1 \mathrm{AD}$ per cell. They are shown in Fig. 3 and they can be classified according to the distance between $\mathrm{Al}_{\text {oct }}$ and $\mathrm{Y}$ in perfect YAG: 3.386, 5.460, 6.939, and $8.155 \AA$. Their formation energies per antisite defect, $E_{f}(1 \mathrm{AD})$, calculated as the difference between the total energies per unit cell of $1 \mathrm{AD}: \mathrm{YAG}$ and perfect YAG after optimization of the atomic positions of all atoms in both cases, $E(1 \mathrm{AD})-E(\mathrm{YAG})$, are shown in Table II. The data at infinite distance, $E_{f, \infty}(1 \mathrm{AD})$, have been calculated out of the energies of the single substitutional defects $\mathrm{Y}_{\mathrm{Al}}$ and $\mathrm{Al}_{\mathrm{Y}}$ : $E\left(\mathrm{Al}_{\mathrm{Y}}: \mathrm{YAG}\right)+E\left(\mathrm{Y}_{\mathrm{Al}}: \mathrm{YAG}\right)-2 E(\mathrm{YAG})$. We can observe that the most stable single AD corresponds to the shortest distance between $\mathrm{Al}$ and $\mathrm{Y}$, which means an effective attraction between the single substitutional defects $\mathrm{Y}_{\mathrm{Al}}$ and $\mathrm{Al}_{\mathrm{Y}}$. Binding energies within the substitutional defect with respect to the isolated defects situation, $E_{b}(1 \mathrm{AD})$, are reflected in Table II, showing an attraction energy of $0.74 \mathrm{eV}$ for the most stable single AD.

This is what one expects of the electrostatic interaction between these defects because (a) they are both uncharged and (b) the individual substitutions do not change basically 


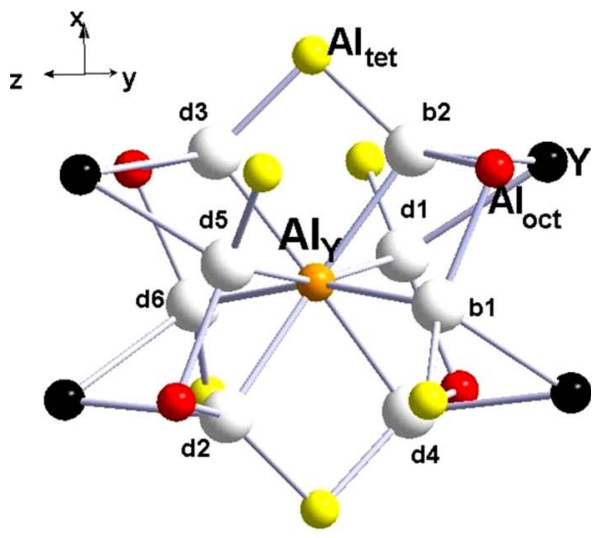

TABLE I. Al-O, Y-O, and Al-Y distances, in $\AA$, in perfect YAG, single substitutional defects $\mathrm{Al}_{\mathrm{Y}}$ and $\mathrm{Y}_{\mathrm{Al}}$, and most stable single antisite defect. Atomic labels used in Fig. 4 are indicated.

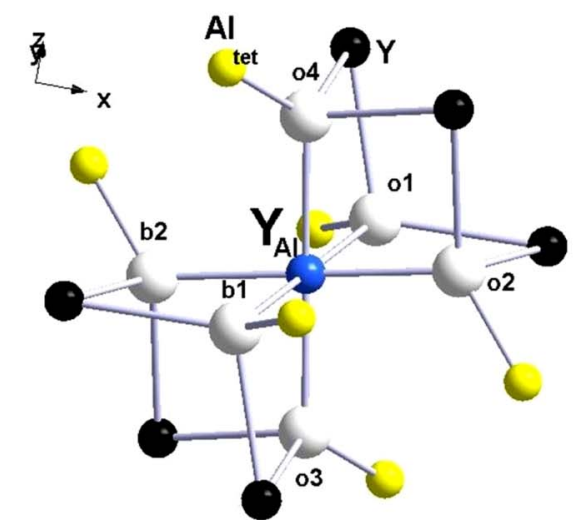

FIG. 2. (Color online) Single substitutional defects. Top: Al atom in $\mathrm{Y}$ site $\left[\mathrm{Al}_{\mathrm{Y}}\right.$ orange (medium-light gray)]. Bottom: $\mathrm{Y}$ atom in $\mathrm{Al}_{\text {oct }}$ site $\left[\mathrm{Y}_{\mathrm{Al}}\right.$ blue (medium-dark gray)]. First coordination shell (white oxygen atoms) and second coordination shell [black $\mathrm{Y}$ atoms, yellow (light gray) $\mathrm{Al}_{\text {tet }}$ atoms, and red (dark gray) $\mathrm{Al}_{\text {oct }}$ atoms] are shown. Oxygens labeled d1-d6 correspond to the original dodecahedral site and o1-04 to the original octahedral site. Oxygens $\mathrm{b} 1$ and $\mathrm{b} 2$ will be bridge atoms between $\mathrm{Al}_{\mathrm{Y}}$ and $\mathrm{Y}_{\mathrm{Al}}$ in the most stable antisite defect (see below).

the symmetry and the orientations of the multipoles of the two sites. So, the static electrostatic interactions between them (meaning the interactions between the $\mathrm{Y}_{\mathrm{Al}}$ and $\mathrm{Al}_{\mathrm{Y}}$ defects without any deformations induced by their mutual interaction) should basically be the same as the interaction between $\mathrm{Y}$ and $\mathrm{Al}$ in perfect YAG. Then, the attractive interaction between the induced multipoles would be dominant. In other words, the elastic deformations around $\mathrm{Y}_{\mathrm{Al}}$ and $\mathrm{Al}_{\mathrm{Y}}$ due to their mutual interaction in $\mathrm{Y}_{\mathrm{Al}}-\mathrm{Al}_{\mathrm{Y}}$ antisite defects are such that they attract each other. Although we like to think in electrostatic terms because all observations fit the paradigm very naturally, strain-mediated interactions between the substitutional defects could also be responsible for their attraction. This is clearly the case at very short distances since coordination rearrangements of both defects are benefiting from each other's presence (see below).

According to these first-principles calculations, the formation of a single antisite defect is a very endothermic process $(3.72-4.32 \mathrm{eV} / \mathrm{defect}$ and $360-415 \mathrm{~kJ} / \mathrm{mol})$. The available pair-potential simulations led to a significantly less endothermic antisite-defect formation energy $(0.9 \mathrm{eV} / \mathrm{defect}$ and $87 \mathrm{~kJ} / \mathrm{mol}) .{ }^{11}$ Although the first-principles value could be

\begin{tabular}{|c|c|c|c|}
\hline \multicolumn{4}{|c|}{ Dodecahedral site } \\
\hline & YAG & $\mathrm{Al}_{\mathrm{Y}}: \mathrm{YAG}$ & 1AD:YAG \\
\hline Oxygen & $d(\mathrm{Y}-\mathrm{O})$ & $d\left(\mathrm{Al}_{\mathrm{Y}^{-}-\mathrm{O}}\right)$ & $d\left(\mathrm{Al}_{\mathrm{Y}^{-}} \mathrm{O}\right)$ \\
\hline d1 & 2.446 & 2.384 & 3.216 \\
\hline b1 & 2.446 & 2.383 & 2.889 \\
\hline $\mathrm{d} 2$ & 2.333 & 2.150 & 2.314 \\
\hline $\mathrm{d} 3$ & 2.333 & 2.150 & 2.189 \\
\hline $\mathrm{b} 2$ & 2.333 & 2.150 & 2.064 \\
\hline $\mathrm{d} 4$ & 2.333 & 2.147 & 2.058 \\
\hline d5 & 2.446 & 2.374 & 1.964 \\
\hline \multirow{8}{*}{ d6 } & 2.446 & 2.375 & 1.954 \\
\hline & $d\left(\mathrm{Y}-\mathrm{Al}_{\mathrm{tet1}}\right)$ & $d\left(\mathrm{Al}_{\mathrm{Y}}-\mathrm{Al}_{\mathrm{tet} 1}\right)$ & $d\left(\mathrm{Al}_{\mathrm{Y}^{-}}-\mathrm{Al}_{\text {tet } 1}\right)$ \\
\hline & 3.028 & 2.963 & 3.000 \\
\hline & $d\left(\mathrm{Al}_{\left.\mathrm{tet} 1^{-} \mathrm{O}\right)}\right.$ & $d\left(\mathrm{Al}_{\operatorname{tet} 1}-\mathrm{O}\right)$ & $d\left(\mathrm{Al}_{\mathrm{tet} 1}-\mathrm{O}\right)$ \\
\hline & $1.79 \times 4$ & $1.80-1.81$ & $1.80-1.83$ \\
\hline & \multicolumn{2}{|c|}{ Octahedral site } & \\
\hline & YAG & $\mathrm{Y}_{\mathrm{Al}}: \mathrm{YAG}$ & 1AD:YAG \\
\hline & $d\left(\mathrm{Al}_{\mathrm{oct}^{-}} \mathrm{O}\right)$ & $d(\mathrm{Y}-\mathrm{O})$ & $d\left(\mathrm{Y}_{\mathrm{Al}^{-}} \mathrm{O}\right)$ \\
\hline o1 & 1.947 & 2.176 & 2.233 \\
\hline 02 & 1.947 & 2.176 & 2.226 \\
\hline o3 & 1.947 & 2.176 & 2.223 \\
\hline b2 & 1.947 & 2.176 & 2.211 \\
\hline o4 & 1.947 & 2.176 & 2.186 \\
\hline b1 & 1.947 & 2.176 & 2.128 \\
\hline$d 3^{a}$ & 4.313 & 4.328 & 4.204 \\
\hline \multirow[t]{7}{*}{$d 1^{a}$} & 3.784 & 3.778 & 3.783 \\
\hline & $d\left(\mathrm{Al}_{\text {oct }}-\mathrm{Al}_{\text {tet } 2}\right)$ & $d\left(\mathrm{Y}_{\mathrm{Al}^{-}}-\mathrm{Al}_{\mathrm{tet} 2}\right)$ & $d\left(\mathrm{Y}_{\mathrm{Al}}-\mathrm{Al}_{\mathrm{tet} 2}\right)$ \\
\hline & 3.385 & 3.458 & 3.442 \\
\hline & $d\left(\mathrm{Al}_{\mathrm{tet}^{2}}-\mathrm{O}\right)$ & $d\left(\mathrm{Al}_{\mathrm{tet} 2}-\mathrm{O}\right)$ & $d\left(\mathrm{Al}_{\text {tet } 2}-\mathrm{O}\right)$ \\
\hline & $1.79 \times 4$ & $1.78-1.80$ & $1.75-1.78$ \\
\hline & $d\left(\mathrm{Y}-\mathrm{Al}_{\mathrm{oct}}\right)$ & & $d\left(\mathrm{Y}_{\mathrm{Al}}-\mathrm{Al}_{\mathrm{Y}}\right)$ \\
\hline & 3.384 & & 3.655 \\
\hline
\end{tabular}

$\overline{{ }^{a} \text { This oxygen does not belong to the first, sixfold coordination shell }}$ of $\mathrm{Al}_{\text {oct }}$ in YAG.

overestimated, it seems to indicate that the concentration of these entropic established defects is determined at high temperatures (close to the temperature of crystal growth) since they get kinetically trapped at lower temperatures by large energy barriers. Overestimation of the antisite-defect formation energy seems to be due to an overestimation of the formation energies of the two $\mathrm{Y}_{\mathrm{Al}}$ and $\mathrm{Al}_{\mathrm{Y}}$ single substitutional defects. When these are formed, the initial $\mathrm{AlO}_{6}$ and $\mathrm{YO}_{8}$ moieties contain more covalent bonding than the final moieties $\mathrm{YO}_{6}$ and $\mathrm{AlO}_{8}$ because $\mathrm{AlO}_{6}$ is more covalent than $\mathrm{YO}_{8}, \mathrm{YO}_{6}$, and $\mathrm{AlO}_{8}$, and the PBE functional does not seem to be sufficiently accurate to describe the energetics of this bond rearrangement. Although basis set and pseudopotentials certainly contribute to the errors in these numbers, the con- 

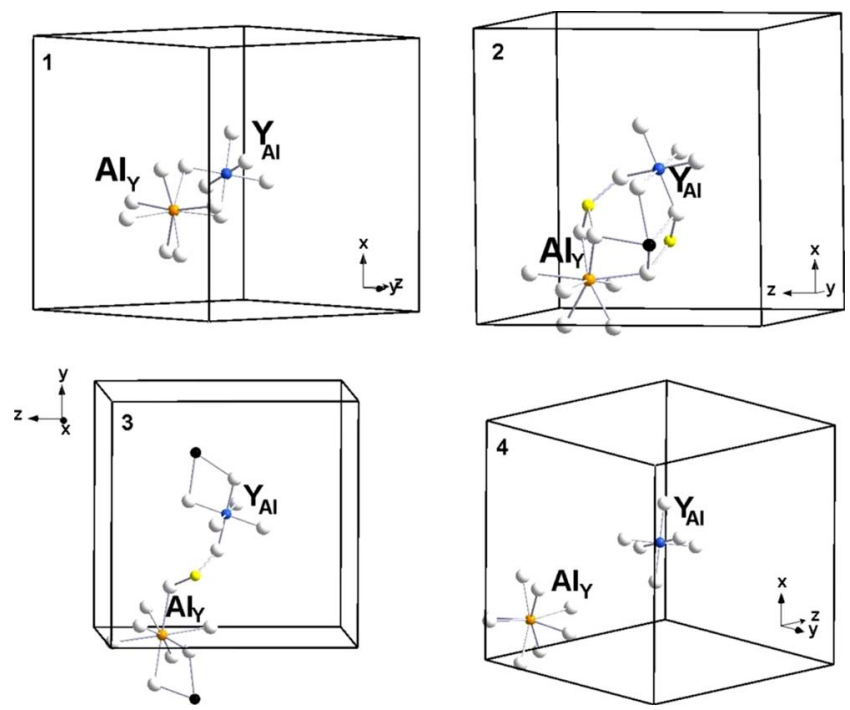

FIG. 3. (Color online) The four possible 1AD:YAG, ordered according to the Y-Al distance before relaxation: (1) $3.39 \AA$, (2) $5.46 \AA$, (3) $6.94 \AA$, and (4) $8.16 \AA$. First coordination shell (white oxygen atoms) and, where appropriate, black $\mathrm{Y}$ atoms and yellow (light gray) $\mathrm{Al}_{\text {tet }}$ shared atoms of the second coordination shell shown.

vergence tests performed on these point to the exchangecorrelation approximations as the main cause of the deviation. Hybrid functionals are expected to perform better for this purpose. However, after the single substitutional defects are formed, their mutual attraction does not involve important bond changes and we should expect the PBE functional to perform well and to accurately predict the relative energies of different ADs and the binding energies between $\mathrm{Y}_{\mathrm{Al}}$ and $\mathrm{Al}_{\mathrm{Y}}$. The same will be true for the interaction between two ADs.

Relaxation energies, $E_{r}(1 \mathrm{AD})$, are also shown in Table II. They are defined as the energies of each relaxed structure, $E(1 \mathrm{AD})$, minus the energy of the corresponding stressed structures after $\mathrm{Y}$ and $\mathrm{Al}$ exchange their positions, $E_{0}(1 \mathrm{AD})$. They are within the -6.18 to $-5.56 \mathrm{eV} /$ defect range and follow the same pattern as formation energies do. Thus, the fact that the more favorable the relaxation energy is, the more stable the AD structure is, suggests an important role of the flexibility of the local environments around YAG positions.

Let us comment on the structure of the most stable single antisite defect, which is shown in Fig. 4 and Table $\mathrm{I}$. $\mathrm{Al}_{\mathrm{Y}}$ shows a strong preference for a sixfold coordination, attracting six of the oxygens to shorter distances (1.95-2.31 $\AA$ ), closer to the $\mathrm{Al}_{\text {oct }} \mathrm{O}$ distance in perfect YAG $(1.95 \AA)$ and pushing the other two oxygens $\left(\mathrm{O}_{\mathrm{b} 1}\right.$ and $\left.\mathrm{O}_{\mathrm{d} 1}\right)$ away to nonbonding distances (2.89 and $3.22 \AA$ ), something that can be realized because of the presence of $\mathrm{Y}_{\mathrm{Al}}$ (note that single $\mathrm{Al}_{\mathrm{Y}}$ defects maintain coordination 8 , Table I). At the same time, $\mathrm{Y}_{\mathrm{Al}}$ forces the six surrounding oxygens to move outward (2.13-2.23 $\AA$ ) to distances closer to the original dodecahedral environment in perfect YAG (2.33 and $2.45 \AA)$ but it is not capable of achieving its natural eightfold coordination in YAG. In order to illustrate this, the distances between $\mathrm{Y}_{\mathrm{Al}}$ and its closest oxygens, $\mathrm{O}_{\mathrm{d} 3}$ and $\mathrm{O}_{\mathrm{d} 1}$, are shown (3.78 and $4.20 \AA$ ), which are very similar to the initial $\mathrm{Al}_{\text {oct }}-\mathrm{O}_{\mathrm{d} 3}$ and $\mathrm{Al}_{\text {oct }}-\mathrm{O}_{\mathrm{d} 1}$ distances $(3.78$ and $4.31 \AA$ ). Together with these deformations around $\mathrm{Al}_{\mathrm{Y}}$ and $\mathrm{Y}_{\mathrm{Al}}$, the $\mathrm{Y}-\mathrm{Al}$ distance is significantly increased (from 3.38 to $3.66 \AA$ ), as a consequence of a softer shielding of the oxygens on the repulsion between these cations after the rearrangement of the twelve oxygens. In the same line, the $\mathrm{AlO}_{4}$ moieties seem to be flexible enough so as to accommodate the stress produced by the oxygen rearrangement. In fact, the contraction around $\mathrm{Al}_{Y}$ is followed by a shortening of the distance between this site and $\mathrm{Al}_{\text {tet } 1}$, of the adjacent $\mathrm{AlO}_{4}$ moiety that shares two oxygens with the dodecahedron (from 3.03 to $3.00 \AA$ ). This moiety responds with an enlargement of the $\mathrm{Al}_{\text {tet } 1}-\mathrm{O}$ distances (from 1.79 to $1.80-1.83 \AA$ ). In parallel to this, the expansion around $\mathrm{Y}_{\mathrm{Al}}$ is followed by an enlargement of the distance between this site and $\mathrm{Al}_{\text {tet } 2}$, of the adjacent $\mathrm{AlO}_{4}$ moiety which shares two oxygens with the octahedron (from 3.39 to $3.44 \AA$ ). This moiety responds with a shortening of the $\mathrm{Al}_{\text {tet } 1}-\mathrm{O}$ distances (from 1.79 to $1.75-1.78 \AA$ ), all of it resulting in a minimization of the displacements of the oxygens in the third coordination shell of the $\mathrm{Y}_{\mathrm{Al}^{-}}-\mathrm{Al}_{\mathrm{Y}}$ antisite defect and a negligible distortion beyond that shell.

\section{Electronic structure}

The band structure of 1AD:YAG does not show important changes with respect to perfect YAG. ${ }^{13,18}$ The total density of states (DOS) of the most stable 1AD:YAG and YAG are shown together in Fig. 5(a), where the zero reference corresponds to YAG's top of the valence band. No significant differences between 1AD:YAG and YAG are observed in Fig. 5(a); the main characters of the peaks are $\mathrm{Y} 4 p$ at $-20 \mathrm{eV}, \mathrm{O} 2 s$ at $-16 \mathrm{eV}, \mathrm{O} 2 p$ between -6 and $0 \mathrm{eV}$, and $\mathrm{Y} 5 s$ and $5 d$ at the bottom of the conduction band. However, a closer look at the highest valence and lowest conduction states [Fig. 5(b)] reveals interesting features: some of the valence states split up by the AD formation, introducing defect levels in the gap shifted upward $0.25 \mathrm{eV}$ with respect to the perfect YAG highest valence levels. An analysis of the oxygen projected DOS (PDOS) of 1AD:YAG shows that it is almost identical to the total DOS in the highest-energy region of the valence as it was the case in YAG, ${ }^{18}$ which indicates that the gap reduction is due to changes in the electronic structure of the oxygen atoms. A Mulliken population analysis $^{30}$ of the 12 oxygens directly involved in the AD formation does not show any significant differences in the change of their total and overlap populations; however, the PDOS of the individual oxygens are revealing. They are shown in Fig. 5(c) together with the PDOS of oxygen in perfect YAG. It can be observed that the states on the three oxygens which remain at a long distance from $\mathrm{Al}_{\mathrm{Y}}\left(\mathrm{O}_{\mathrm{d} 2}, \mathrm{O}_{\mathrm{b} 1}\right.$, and $\mathrm{O}_{\mathrm{d} 1}$ ) increase their energy, the longer the distance the larger the energy increase, with a very significant change in the two oxygens at $2.9 \AA\left(\mathrm{O}_{\mathrm{b} 1}\right)$ and $3.2 \AA\left(\mathrm{O}_{\mathrm{d} 1}\right)$; these are very long compared with usual Al-O distances and the two oxygens might be considered basically unbound to $\mathrm{Al}_{\mathrm{Y}} \cdot \mathrm{O}_{\mathrm{b} 1}$ and $\mathrm{O}_{\mathrm{d} 1}$ present a very similar PDOS profile, though shifted with respect to each other. Of these two oxygens, $\mathrm{O}_{\mathrm{b} 1}$ was initially a bridge atom sharing the coordinations of the ref- 
TABLE II. Calculated defect formation energies, $E_{f}$, and relaxation energies, $E_{r}$, in eV per antisite defect. In parentheses, differences with respect to structure A1. Calculated binding energies, $E_{b}$, between $\mathrm{Y}_{\mathrm{Al}}$ and $\mathrm{Al}_{\mathrm{Y}}$ in $1 \mathrm{AD}: \mathrm{YAG}$ and between single ADs in $2 \mathrm{AD}: \mathrm{YAG}$, in $\mathrm{eV} .1 \mathrm{eV} / \operatorname{defect}=96.4853 \mathrm{~kJ} / \mathrm{mol}$.

\begin{tabular}{|c|c|c|c|c|c|}
\hline \multirow{3}{*}{$\frac{\text { Structure }}{\text { Figure } 3}$} & \multicolumn{4}{|c|}{ 1AD:YAG } & \multirow[b]{3}{*}{$E_{b}(1 \mathrm{AD})^{\mathrm{c}}$} \\
\hline & \multicolumn{2}{|c|}{$d\left(\mathrm{Y}_{\mathrm{Al}}-\mathrm{Al}_{\mathrm{Y}}\right) / \AA$} & \multirow[b]{2}{*}{$E_{f}(1 \mathrm{AD})^{\mathrm{a}}$} & \multirow[b]{2}{*}{$E_{r}(1 \mathrm{AD})^{\mathrm{b}}$} & \\
\hline & YAG & $1 \mathrm{AD}$ & & & \\
\hline 1 & 3.39 & 3.65 & $3.72(0.11)$ & $-6.18(0.14)$ & 0.74 \\
\hline 2 & 5.46 & 5.33 & $4.02(0.41)$ & $-5.86(0.46)$ & 0.44 \\
\hline 3 & 6.94 & 6.50 & $4.08(0.47)$ & $-5.81(0.51)$ & 0.36 \\
\hline 4 & 8.16 & 8.16 & $4.32(0.71)$ & $-5.56(0.76)$ & 0.14 \\
\hline & $\infty$ & $\infty$ & $4.46(0.85)$ & $-5.44(0.88)$ & \\
\hline
\end{tabular}

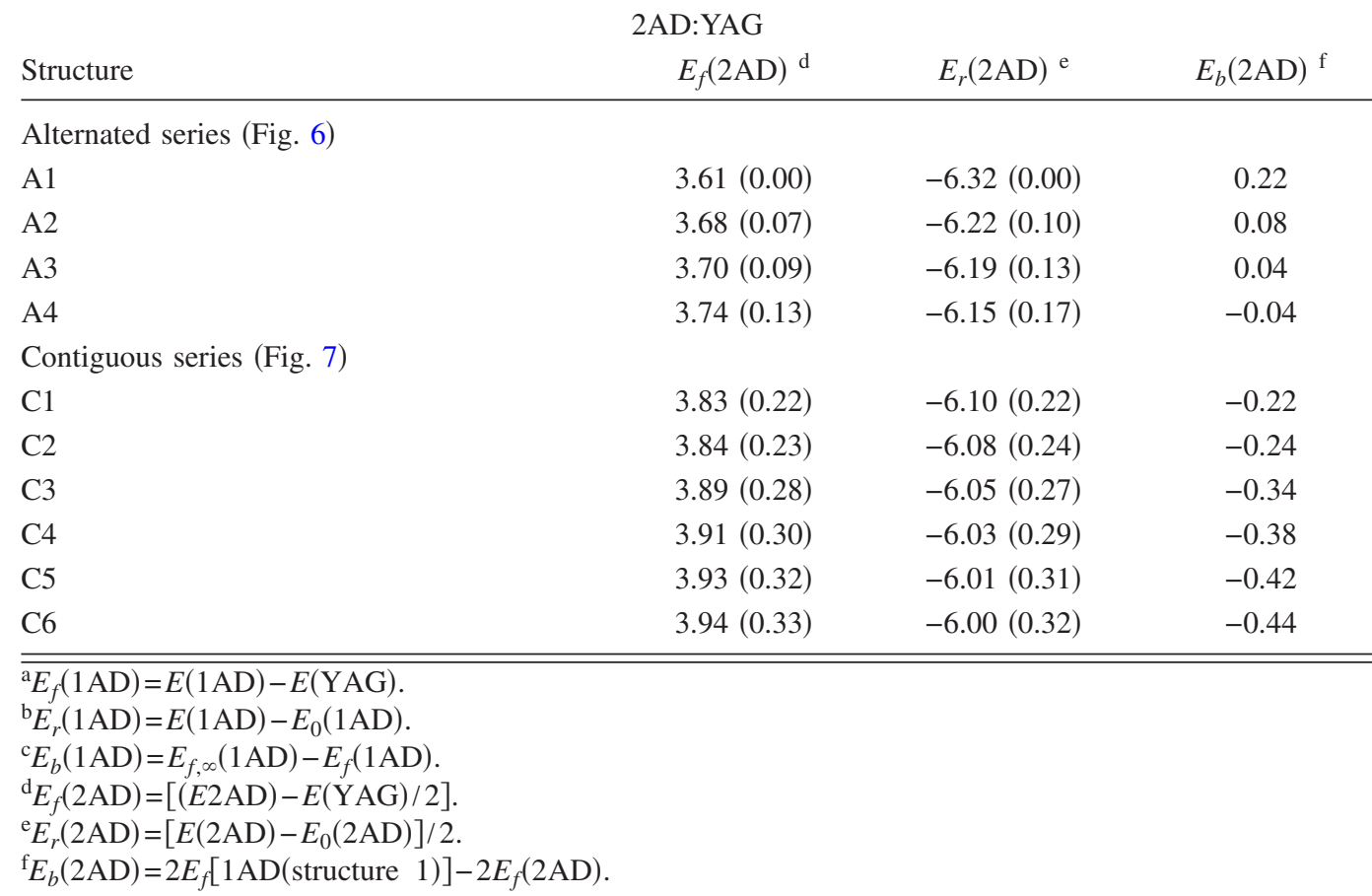

erence $\mathrm{Y}$ and $\mathrm{Al}$ atoms in $\mathrm{YAG}$ and it becomes unbound to $\mathrm{Al}_{\mathrm{Y}}$ and remains bound only to $\mathrm{Y}_{\mathrm{Al}}$ in $1 \mathrm{AD}$ :YAG (besides to the other two on-site atoms $\mathrm{Y}$ and $\mathrm{Al}_{\text {tet }}$; note that each $\mathrm{O}$

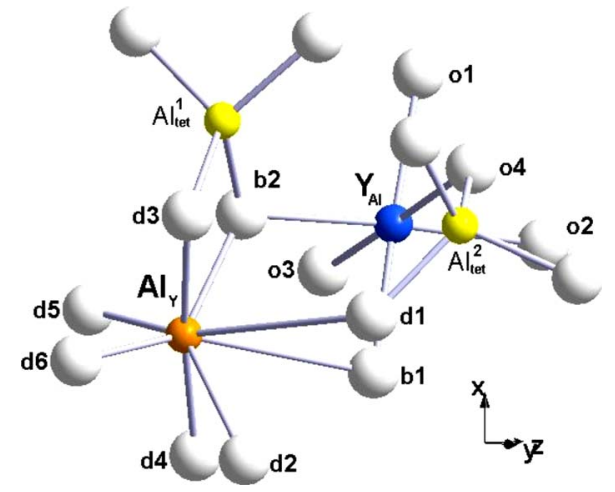

FIG. 4. (Color online) Relaxed structure of the most stable 1AD:YAG [Fig. 3 (1)]. $\mathrm{Al}_{\mathrm{Y}}$ [orange (medium-light gray)], $\mathrm{Y}_{\mathrm{Al}}$ [blue (medium-dark gray)], and adjacent $\mathrm{Al}_{\text {tet }}$ atoms [yellow (light gray)] shown. Oxygen labels according to Fig. 2. atom in $\mathrm{YAG}$ is bound to one $\mathrm{Al}_{\mathrm{oct}}$, one $\mathrm{Al}_{\text {tet }}$, and two $\mathrm{Y}$ atoms). $\mathrm{O}_{\mathrm{d} 1}$, however, which was not bound to the reference $\mathrm{Al}_{\text {oct }}$ atom in YAG and was only bound to the reference $\mathrm{Y}$, is now basically unbound to $\mathrm{Al}_{\mathrm{Y}}$ in $1 \mathrm{AD}$ :YAG. It is around this oxygen where the highest valence states $0.25 \mathrm{eV}$ above those of YAG are localized.

\section{B. Two antisite defects per unit cell, 2AD:YAG}

\section{Structure}

The study of two antisite defects per unit cell, 2AD:YAG, is largely simplified by considering only $\mathrm{AD}$ pairs made of the most stable single $\mathrm{ADs}$, where $\mathrm{Y}_{\mathrm{Al}}$ and $\mathrm{Al}_{\mathrm{Y}}$ lie at the closest distance (Sec. III A). This, together with the fact that the crystal belongs to the trigonal $R \overline{3}$ space group, ${ }^{4}$ reduces the number of 2AD:YAG cases to ten. This is so because the [111] axis, which is a $\overline{3}$ symmetry axis, contains no $\mathrm{Y}$ (c) sites and four $\mathrm{Al}_{\mathrm{oct}}$ (a) sites, which forces the two $\mathrm{Y}_{\mathrm{Al}}$ to be located along the [111] axis and the two corresponding $\mathrm{Al}_{\mathrm{Y}}$ to distribute randomly around it. The ten cases may be 


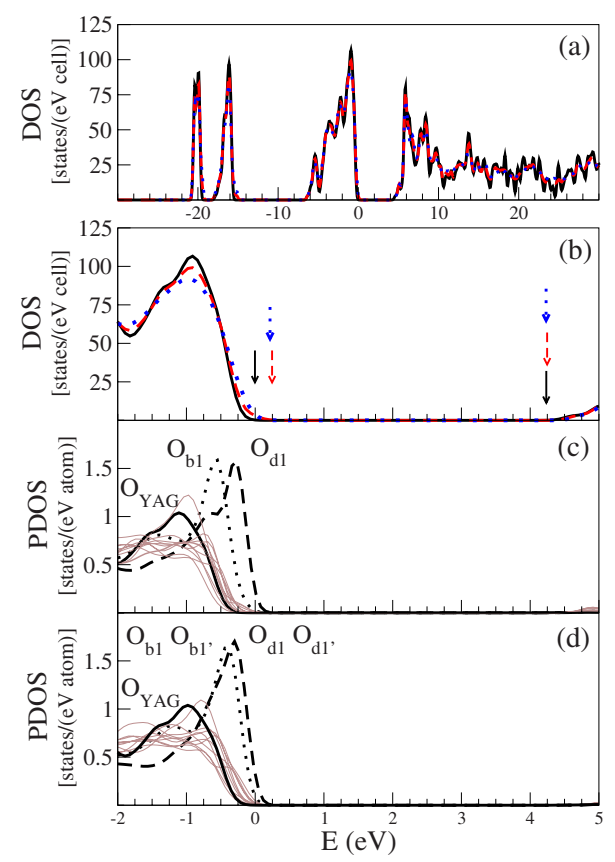

FIG. 5. (Color online) (a) Total DOS of YAG (black solid line), 1AD:YAG (red dashed line), and 2AD:YAG (blue dotted line). (b) Zoom over the gap zone. Vertical arrows indicate the end of the valence bands and the beginning of the conduction bands [same lines as in (a)]. (c) PDOS for the 1AD:YAG oxygen atoms shown in Fig. 4. (d) PDOS for the 2AD:YAG oxygen atoms shown in Fig. 8. In (c) and (d), dashed and dotted lines are used for the distinctive oxygens with indicated labels; thin lines are used for the remaining oxygens of the respective figures. The oxygen PDOS of perfect YAG is shown as a reference.

grouped in a series of four cases where the two $\mathrm{Y}_{\mathrm{Al}}$ substitutions are alternated (Fig. 6) and another series of six cases where they are contiguous (Fig. 7).

The formation energies per AD of all the ten cases, $E_{f}(2 \mathrm{AD})$, calculated out of the total energies per unit cell of the relaxed structures as $[E(2 \mathrm{AD})-E(\mathrm{YAG}) / 2]$, corresponding relaxation energies per $\mathrm{AD}, E_{r}(2 \mathrm{AD})$, and binding energies between the two single $\mathrm{ADs}, E_{b}(2 \mathrm{AD})$, in each studied 2AD:YAG case are shown in Table II. According to these calculations, two independent single ADs attract each other so that the most stable 2AD:YAG is energetically more favorable than two separated single ADs with a binding energy of $0.22 \mathrm{eV}(0.11 \mathrm{eV} / \mathrm{AD}$ and $10.7 \mathrm{~kJ} / \mathrm{mol})$. This situation presents as well the most favorable relaxation energy per AD. From binding energies in Table II, it can be observed that not all the $2 \mathrm{AD}$ configurations are binding. The alternated distribution of the $\mathrm{ADs}$, with the atomic sequence $\cdots-\mathrm{Al}_{\mathrm{oct}}-\mathrm{Y}_{\mathrm{Al}^{-}}-\mathrm{Al}_{\mathrm{oct}^{-}} \mathrm{Y}_{\mathrm{Al}^{2}} \cdots$ all along the [111] axis, is more stable than the contiguous distribution, with the atomic sequence $\cdots-\mathrm{Al}_{\text {oct }}-\mathrm{Al}_{\mathrm{oct}}-\mathrm{Y}_{\mathrm{Al}^{-}}-\mathrm{Y}_{\mathrm{Al}^{-}} \cdots$. Forming pairs of adjacent ADs has an energy cost of $0.2-0.3 \mathrm{eV} /$ defect $(20-30 \mathrm{~kJ} / \mathrm{mol})$ over distributing them evenly along the [111] axis. On the other hand, the energies of all the alternated structures are not very different. The two alternated structures whose $\mathrm{Y}_{\mathrm{Al}^{-}} \mathrm{Al}_{\mathrm{Y}}$ vectors have an antiparallel projection on the [111] axis (A1 and A2), and somehow tend to oppose each other
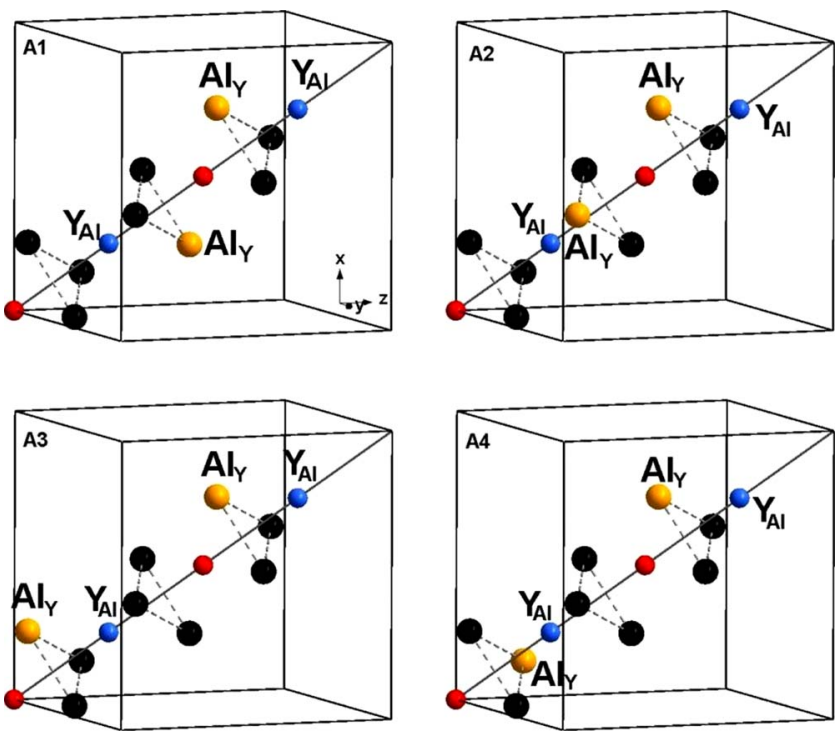

FIG. 6. (Color online) Studied double 1AD:YAG with alternated $\mathrm{Y}_{\mathrm{Al}}$ positions. [111] axis shown. Positions before structural relaxation. Colors: $\mathrm{Al}_{\mathrm{Y}}$ atoms, orange (medium-light gray); $\mathrm{Y}_{\mathrm{Al}}$ atoms, blue (medium-dark gray); $\mathrm{Y}$ atoms, black; and $\mathrm{Al}_{\text {oct }}$ atoms, red (dark gray).

and diminish the local dipole moment, are more stable than the other two alternated structures (A3 and A4), whose $\mathrm{Y}_{\mathrm{Al}}-\mathrm{Al}_{\mathrm{Y}}$ vectors have a parallel projection on the [111] axis and tend to back each other and increase the local dipole moment. Among all, the most stable structure is A1, which is shown in Fig. 8 and is the only one with inversion symmetry respect to the unit-cell center. Because of this, it is the only structure of 2AD:YAG with zero local dipole moment with respect to $(1 / 2,1 / 2,1 / 2)$. Some of its structural details are presented in Table III. The local structures of the two antisite defects are identical as a consequence of the inversion center at the $\mathrm{Al}_{\text {oct }}(1 / 2,1 / 2,1 / 2)$ site and they are very similar to the structure of a single AD. In particular, they show the interesting features of one bridge oxygen between $\mathrm{Al}$ and $\mathrm{Y}$ becoming only bound to $\mathrm{Y}_{\mathrm{Al}}\left(\mathrm{O}_{\mathrm{b} 1}\right.$ and $\left.\mathrm{O}_{\mathrm{b} 1}{ }^{\prime}\right)$ and one oxygen initially bound to $\mathrm{Y}$ becoming unbound to $\mathrm{Al}_{\mathrm{Y}}\left(\mathrm{O}_{\mathrm{d} 1}\right.$ and $\left.\mathrm{O}_{\mathrm{d} 1^{\prime}}\right)$. In this structure, the $\mathrm{Al}_{\mathrm{oct}}$ atom linking the two ADs seems to play an important role in its stability because the $\mathrm{Al}_{\text {oct }}-\mathrm{O}$ distances shorten from the initial value in $\mathrm{YAG}$, $1.95 \AA$, to $1.89,1.91$, and $1.94 \AA$, closer to Al-O distances in other compounds, such as $1.86 \AA$ in $\mathrm{Al}_{2} \mathrm{O}_{3}$ (Ref. 31) and $1.89 \AA$ in $\mathrm{LaAlO}_{3}{ }^{32}$

\section{Electronic structure}

The total DOS of the most stable 2AD:YAG structure (A1) is shown in Figs. 5(a) and 5(b). The same features observed in 1AD:YAG are reproduced in 2AD:YAG, presenting defect levels in the gap, which results from an energy shift of approximately $0.21 \mathrm{eV}$ of the two oxygen atoms $\mathrm{O}_{\mathrm{b} 1}$ and $\mathrm{O}_{\mathrm{d} 1}$ (and their symmetry equivalents $\mathrm{O}_{\mathrm{b} 1^{\prime}}$ and $\mathrm{O}_{\mathrm{d} 1^{\prime}}$ ), which correspond to oxygens $\mathrm{O}_{\mathrm{b} 1}$ and $\mathrm{O}_{\mathrm{d} 1}$ in 1AD:YAG and are unbound to $\mathrm{Al}_{Y}$, as it is demonstrated in the PDOS in Fig. 5(d). In other words, the most stable 2AD:YAG structure shows basically the same electronic structure as 

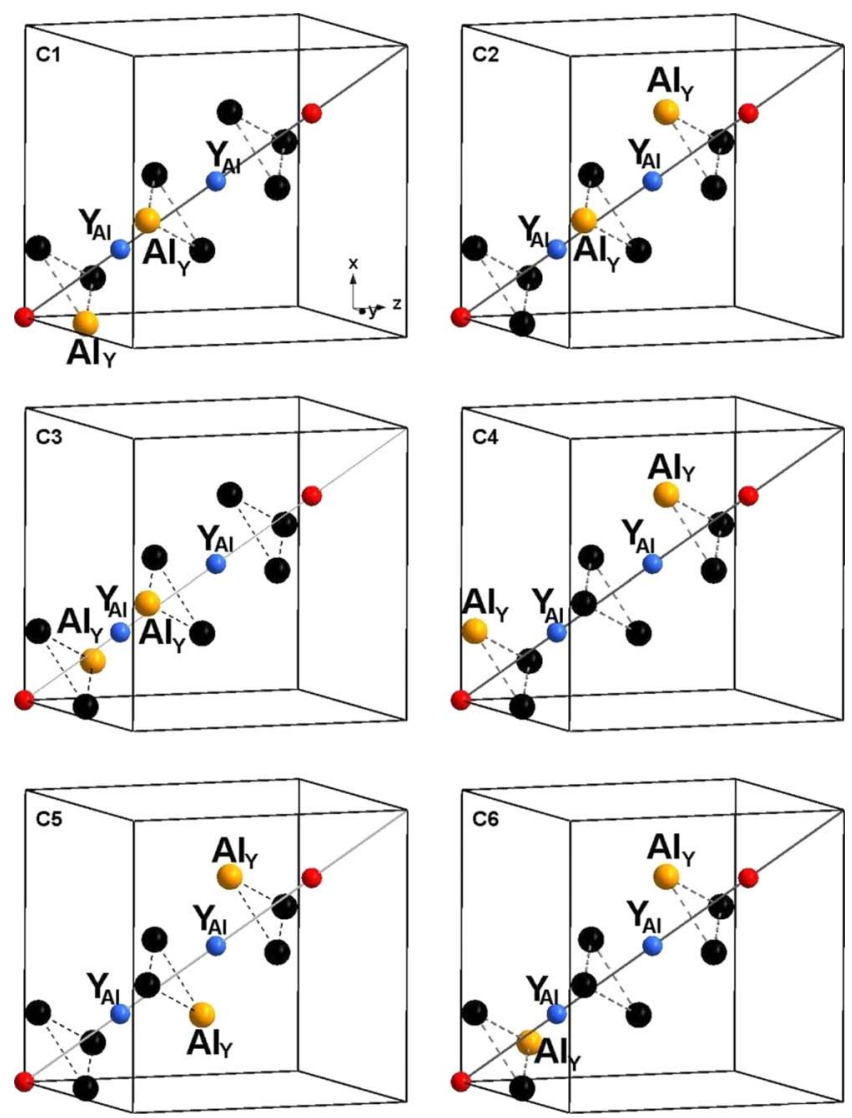

FIG. 7. (Color online) Studied double $1 \mathrm{AD}$ :YAG with contiguous $\mathrm{Y}_{\mathrm{Al}}$ positions. [111] axis shown. Positions before structural relaxation. Colors: $\mathrm{Al}_{\mathrm{Y}}$ atoms, orange (medium-light gray); $\mathrm{Y}_{\mathrm{Al}}$ atoms, blue (medium-dark gray); $\mathrm{Y}$ atoms, black; and $\mathrm{Al}_{\text {oct }}$ atoms, red (dark gray).

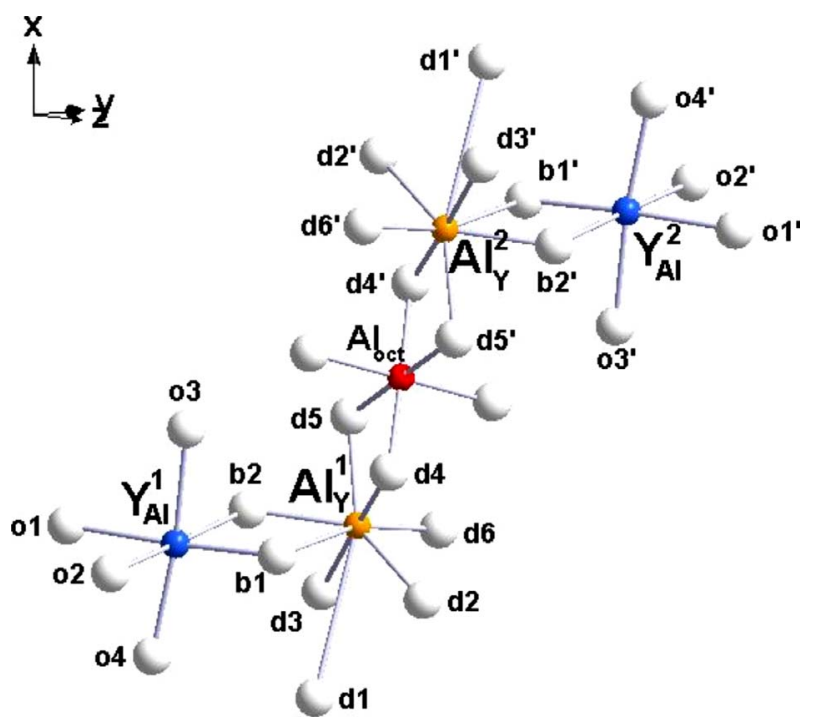

FIG. 8. (Color online) Relaxed structure of the most stable 2AD:YAG [Fig. 6 (A1)]. $\mathrm{Al}_{\mathrm{Y}}$ [orange (medium-light gray)], $\mathrm{Y}_{\mathrm{Al}}$ [blue (medium-dark gray)], and linking $\mathrm{Al}_{\mathrm{oct}}$ atom [red (dark gray)] shown. Oxygen labels according to Fig. 2.
TABLE III. Al-O and Y-O distances of the most stable 2AD:YAG structure (Fig. 8), in $\AA$.

\begin{tabular}{lcccc}
\hline \hline \multicolumn{2}{c}{ Dodecahedral sites } & & \multicolumn{2}{c}{ Octahedral sites } \\
\cline { 1 - 2 } \cline { 5 - 5 } Oxygen & $d\left(\mathrm{Al}_{\mathrm{Y}^{-}} \mathrm{O}\right)$ & & Oxygen & $d\left(\mathrm{Y}_{\mathrm{Al}^{-}} \mathrm{O}\right)$ \\
\hline $\mathrm{d} 1$ & 3.34 & & $\mathrm{o} 1$ & 2.22 \\
$\mathrm{~b} 1$ & 2.86 & & $\mathrm{o} 2$ & 2.22 \\
$\mathrm{~d} 2$ & 2.10 & & $\mathrm{o} 3$ & 2.22 \\
$\mathrm{~d} 3$ & 2.17 & & $\mathrm{~b} 2$ & 2.21 \\
$\mathrm{~b} 2$ & 2.06 & & $\mathrm{o} 4$ & 2.19 \\
$\mathrm{~d} 4$ & 2.06 & & $\mathrm{~b} 1$ & 2.12 \\
$\mathrm{~d} 5$ & 2.08 & & $\mathrm{~d} 3^{\mathrm{a}}$ & 4.19 \\
$\mathrm{~d} 6$ & 1.97 & & $\mathrm{~d} 1^{\mathrm{a}}$ & 3.86 \\
\hline \hline
\end{tabular}

$\overline{\text { aThis oxygen does not belong to the first, sixfold coordination shell }}$ of $\mathrm{Al}_{\mathrm{oct}}$ in YAG.

1AD:YAG as a consequence of it being made of two almost independent single antisite defects linked by a $\mathrm{AlO}_{6}$ moiety.

\section{CONCLUSIONS}

First-principles DFT-GGA calculations with the PBE functional have been made on the atomistic structure, electronic structure, and distribution of antisite defects in YAG in concentrations of one and two ADs per unit cell. The interactions between the two substitutional defects that make up an $\mathrm{AD}, \mathrm{Y}_{\mathrm{Al}}$ and $\mathrm{Al}_{\mathrm{Y}}$, could in principle be assigned to both electrostatics and mediated by strain. All observations fit in very naturally with induced multipole interactions, although we are aware we have not ruled out other pictures. The most stable single $\mathrm{AD}$ is made of the $\mathrm{Y}_{\mathrm{Al}}$ and $\mathrm{Al}_{\mathrm{Y}}$ as close as possible, presenting a binding energy of $0.74 \mathrm{eV}$ with respect to the individual substitutional defects. While $\mathrm{Y}_{\mathrm{Al}}$ maintains the original sixfold coordination of $\mathrm{AlO}_{6}$ and increases all $\mathrm{Y}_{\mathrm{Al}} \mathrm{O}$ distances, $\mathrm{Al}_{\mathrm{Y}}$ cannot retain two of the eight oxygen atoms of the original $\mathrm{YO}_{8}$ dodecahedral moiety, which move away, and lowers significantly six of the $\mathrm{Al}_{\mathrm{Y}^{-}} \mathrm{O}$ distances, becoming sixfold coordinated. One of the two oxygen atoms which become unbound to $\mathrm{Al}_{Y}$ is one of the two bridge oxygens between $\mathrm{YO}_{8}$ and $\mathrm{AlO}_{6}$ in perfect YAG; the other belongs only to $\mathrm{YO}_{8}$ in YAG. As a consequence of their being less tightly bound to a cation, the upper electronic levels localized in these oxygens shift upward, especially those on the latter, introducing levels in the gap of perfect YAG 0.25 $\mathrm{eV}$ above the top of the valence band. The formations of one and two antisite defects per unit cell are endothermic and the formation energy per defect is lower in 2AD than in 1AD. The most stable 2AD:YAG structure is the only one which preserves the inversion center with respect to $(1 / 2,1 / 2,1 / 2)$ and, in consequence, has zero dipole moment with respect to the unit-cell center. It is made of two single ADs linked by a $\mathrm{AlO}_{8}$ moiety, which seems to play an important role in the stability of the structure. It has basically the same electronic structure as the most stable single $\mathrm{AD}$ and presents a binding energy between the two ADs of $0.22 \mathrm{eV}$. 


\section{ACKNOWLEDGMENTS}

This work was partly supported by a grant from Ministerio de Ciencia e Innovación, Spain (Dirección General de Programas y Transferencia de Conocimiento under Grant No. MAT2008-05379/MAT). These calculations have been performed using the CamGRID computational structure. A.B.M.-G. acknowledges the hospitality and helpfulness of people of the Department of Earth Sciences (University of Cambridge, U.K.) and a contract of the program Personal Investigador en Formación (Comunidad de Madrid).
${ }^{1}$ G. deWith, in High Technology Ceramics, edited by P. Vincenzini (Elsevier, Amsterdam, 1987), p. 2063.

${ }^{2}$ R. C. Powell, Physics of Solid State Laser Materials (AIP, New York, 1998).

${ }^{3}$ T. Justel, H. Nikol, and C. Ronda, Angew. Chem., Int. Ed. 37, 3084 (1998).

${ }^{4}$ J. Dong and K. Lu, Phys. Rev. B 43, 8808 (1991).

${ }^{5}$ F. A. Selim, D. Solodovnikov, M. H. Weber, and K. G. Lynn, Appl. Phys. Lett. 91, 104105 (2007).

${ }^{6}$ V. Babin, K. Blazek, A. Krasnikov, K. Nejezchleb, M. Nikl, T. Savikhina, and S. Zazubovich, Phys. Status Solidi C 2, 97 (2005).

${ }^{7}$ Y. Zorenko, A. Voloshinovskii, I. Konstankevych, V. Kolobanov, V. Mikhailin, and D. Spassky, Radiat. Meas. 38, 677 (2004).

${ }^{8}$ Yu. Zorenko, A. Voloshinovskii, V. Savchyn, T. Voznyak, M. Nikl, K. Nejezchleb, V. Mikhailin, V. Kolobanov, and D. Spassky, Phys. Status Solidi B 244, 2180 (2007).

${ }^{9}$ F. Euler and J. A. Bruce, Acta Crystallogr. 19, 971 (1965).

${ }^{10}$ C. Landron, S. Lefloch, M. Gervais, J. P. Coutures, and D. Bazin, Phys. Status Solidi B 196, 25 (1996).

${ }^{11}$ M. Kuklja, J. Phys.: Condens. Matter 12, 2953 (2000).

${ }^{12}$ C. Milanese, V. Buscaglia, F. Maglia, and U. AnslemiTamburini, Chem. Mater. 16, 1232 (2004).

${ }^{13}$ Y.-N. Xu and W. Y. Ching, Phys. Rev. B 59, 10530 (1999).

${ }^{14}$ G. Pari, A. Mookerjee, and A. K. Bhattacharya, Physica B $\mathbf{3 6 5}$, 163 (2005).

${ }^{15}$ F. Pascale, C. M. Zicovich-Wilson, R. Orlando, C. Roetti, P. Ugliengo, and R. Dovesi, J. Phys. Chem. B 109, 6146 (2005).

${ }^{16}$ M. G. Shelyapina, V. S. Kasperovich, and P. Wolfers, J. Phys. Chem. Solids 67, 720 (2006).

${ }^{17}$ C. L. Freeman, N. L. Allan, and W. van Westrenen, Phys. Rev. B
74, 134203 (2006).

${ }^{18}$ A. B. Muñoz-García, E. Anglada, and L. Seijo, Int. J. Quantum Chem. 109, 1991 (2009).

${ }^{19}$ J. Gracia, L. Seijo, Z. Barandiarán, D. Curulla, H. Niemansverdriet, and W. van Gennip, J. Lumin. 128, 1248 (2008).

${ }^{20} \mathrm{P}$. Hohenberg and W. Kohn, Phys. Rev. 136, B864 (1964).

${ }^{21}$ W. Kohn and L. J. Sham, Phys. Rev. 140, A1133 (1965).

${ }^{22}$ J. M. Soler, E. Artacho, J. D. Gale, A. García, J. Junquera, P. Ordejón, and D. Sánchez-Portal, J. Phys.: Condens. Matter 14, 2745 (2002).

${ }^{23}$ P. Ordejón, E. Artacho, and J. M. Soler, Phys. Rev. B 53, R10441 (1996).

${ }^{24}$ J. P. Perdew, K. Burke, and M. Ernzerhof, Phys. Rev. Lett. 77, 3865 (1996).

${ }^{25}$ J. Perdew, K. Burke, and M. Ernzerhof, Phys. Rev. Lett. 78, 1396 (1997).

${ }^{26}$ N. Troullier and J. L. Martins, Phys. Rev. B 43, 1993 (1991).

${ }^{27}$ L. Kleinman and D. M. Bylander, Phys. Rev. Lett. 48, 1425 (1982).

${ }^{28}$ S. G. Louie, S. Froyen, and M. L. Cohen, Phys. Rev. B 26, 1738 (1982).

${ }^{29}$ E. Anglada, J. M. Soler, J. Junquera, and E. Artacho, Phys. Rev. B 66, 205101 (2002).

${ }^{30}$ R. S. Mulliken, J. Chem. Phys. 23, 1833 (1955).

${ }^{31}$ I. O. T. Goto, O. L. Anderson, and S. Yamamoto, J. Geophys. Res. 94, 7588 (1989).

${ }^{32}$ S. A. Hayward, F. D. Morrison, S. A. T. Redfern, E. K. H. Salje, J. F. Scott, K. S. Knight, S. Tarantino, A. M. Glazer, V. Shuvaeva, P. Daniel, M. Zhang, and M. A. Carpenter, Phys. Rev. B 72, 054110 (2005). 